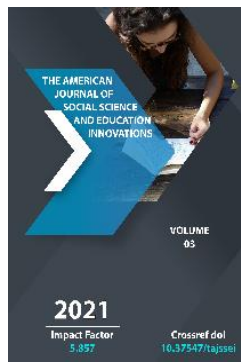

\title{
Relationship Of Theoretical Foundations Of Lexicology And The Development Of Verbal Creativity In Elder Preschool Children
}

\author{
Olga Terekhova \\ Lecturer Of The Department "Pedagogy And Psychology In Preschool Education" Tashkent State \\ Pedagogical University, Tashkent, Uzbekistan
}

Journal Website:

http://usajournalshub.c

om/index,php/tajssei

Copyright: Original content from this work may be used under the terms of the creative commons attributes 4.0 licence.

\section{ABSTRACT}

The word, as a structural unit of language, has a number of basic features. The Russian language is alive, and, like all living things, it develops and undergoes changes in the process of its development. Preschoolers come up with new words based on linguistic patterns. The teacher in the classroom on the development of speech should redirect the word-creation of children in the right direction, showing them the current rules of word-formation of their native language.

\section{KEYWORDS}

Speech, word, vocabulary, abilities, creativity, situational word formation, lexical meaning, synonym, antonym, polysemy, polysemy, neologism, sensitive, perfection.

\section{INTRODUCTION}

It has been proven that creative development is interconnected with speech development, therefore, teaching the native language, activating the child's vocabulary play one of the main roles in deepening his creative skills. 
So, the founder of the Russian scientific school of pedagogy, KD Ushinsky, believed that the development of speech is directly related to the development of thinking [1], because language and thought are one, and in his pedagogical system relied primarily on teaching preschoolers to their native language.

The outstanding psychologist A.R. Luria saw the formation of speech as one of the main factors of the child's mental development and emphasized the role of the mother in this process: "By naming environmental objects, referring to the child with orders and instructions that he obeys, the mother thereby forms his behavior ... Communicating with the mother and following the objects named by her, the child, who acquires independent speech, begins to name these objects himself and thereby gradually forms new means of organizing his active perception and his voluntary attention» [2].

Thus, pointing by the mother to an object and naming it qualitatively change the child's perception, he has an orienting reaction to this object. Integration of a feature of a given object into an already existing system of other objects with similar features contributes to the development of such mental processes as analysis and synthesis, and subsequent fixation in the form of previous experience and a complex system of connections [1]. Before the word becomes the basis for the ability to generalize, the word goes a long way.

\section{MATERIALS AND METHODS}

Over time, the child begins to actively operate with the learned speech constructions: first, the word plays an accompanying role, then it is included in the child's action, later the child masters the word so much that it begins to be of an anticipatory nature. "The above observations show that the independent inclusion of speech in the child's practical activity goes through a number of stages in its development, ending only at the end of preschool age" [2].

A.A. Leontiev in his book "Fundamentals of Psycholinguistics" traced the psychophysiological aspects of the development of speech in children [3]:

1. Preparatory stage (from birth to 1 year) characterized by humming (about 2-3 months) - is part of the "revitalization complex"; babbling (about 5 months) - the physiological mechanism of word formation is formed; pseudoword (about 7 months) - words are not yet associated with objects, but are used to express needs and assess; literature (closer to 1 year) imitation of the speech of an adult, the formation of verbal speech.

2. Preschool stage (1-3 years) characterized by the fact that the child simplifies (distorts) words due to the imperfection of his articulatory apparatus; after a year and a half, the active vocabulary grows due to the complication of the system of functional connections and the improvement of the imitation mechanism; by the age of three, the child partially masters the grammatical structure of word formation.

3. Preschool stage (3-7 years old) characterized by a qualitative leap in the development of the child's speech - all parts of speech are used, word formation skills are formed; the process of mastering the articulation of sounds is completed.

4. School period (7-17 years). 
Summing up the study of the most valuable works of the above teachers, methodologists, linguists and psychologists on the problem of speech development, we can safely conclude that preschoolers should be taught to hear and distinguish sounds, actively use various lexemes and whole sentences in speech, because the child's mental efforts, and also the creative component of this process, provide a reliable basis, including for the development of creative abilities.

Despite the uniqueness of the personality of each child, including its creative side, general patterns of the development of the speech of a preschooler are revealed:

- Situational word formation;

- Awareness and rethinking of the connection between signs and symbols, serving to obtain ideas [4].

Thus, within the framework of speech development classes in kindergarten, vocabulary work is among the priority tasks, it is strongly associated with the formation of epistemological abilities in children and is a prerequisite for creative thinking. And the teacher, as a central figure in this process, must have certain knowledge from the field of lexicology.

The word, as a structural unit of the language, has three main features: phonetic, grammatical and lexical (semantic).

Lexical meaning is the main feature, it is "the content of a word, reflecting in the mind and consolidating in it the idea of an object, property, process, phenomena, etc.» [4].

\section{RESULTS AND DISCUSSION}

The lexical meaning is expressed by a complex complex of properties of the word, as a unit of language, where the main role is assigned to the significative and denotative aspects. The signifying aspect has a connection "Word Concept" and implies the content of the concept, which expresses the essential properties of the object. For example, the concept of "milk" includes the following content: 1) a white liquid used to feed mammals' young; 2) a useful product suitable for drinking; 3) milk is provided by cows, goats and other mammals. The denotational aspect has a connection "Word - Subject" and is realized by highlighting any generalizing features. For example, the word "cat" includes a small animal with four legs and a tail.

The lexical meaning of the word is also revealed in other macrocomponents. Many words have an internal form, when the word itself helps to reveal its formation: "boletus" is a mushroom growing under birches. But, due to the fact that the internal form can be forgotten by native speakers, it is not always possible to determine it.

The pragmatic (connotative-stylistic) aspect has the connection "Word - Man", namely, it gives an emotional and stylistic coloring to the meaning of the word. There can be many spheres of connotation: colloquial, youth, slang, etc. For example, the word "finger" is stylistically neutral. Whereas the sublime word "finger" conveys the emotion of admiration, and the professional-stylistic "distal end of the hand" indicates that our interlocutor is a physician. Thus, the teacher should always rely not only on the lexical meaning of a word, but also on its emotional and stylistic aspect, in order to show the child the versatility of the native language. 
Considering vocabulary as a system, one can trace the relationship between linguistic units. Consider the below diagram.

Syntagmatic relations depend on the context, which clarifies this word and gives unambiguity to its meaning.

We offer to compare three proposals:
1. The student heard the water splashing in the iron ladle and how the child drank long and greedily in large, loud sips, stopping to take a breath. (A. Kuprin). The meaning of the word "water" is a clear liquid that you can drink.

2. Although there is no object in the world that is weaker and softer than water, it can destroy the hardest object (Lao Tzu). Water represents strength.

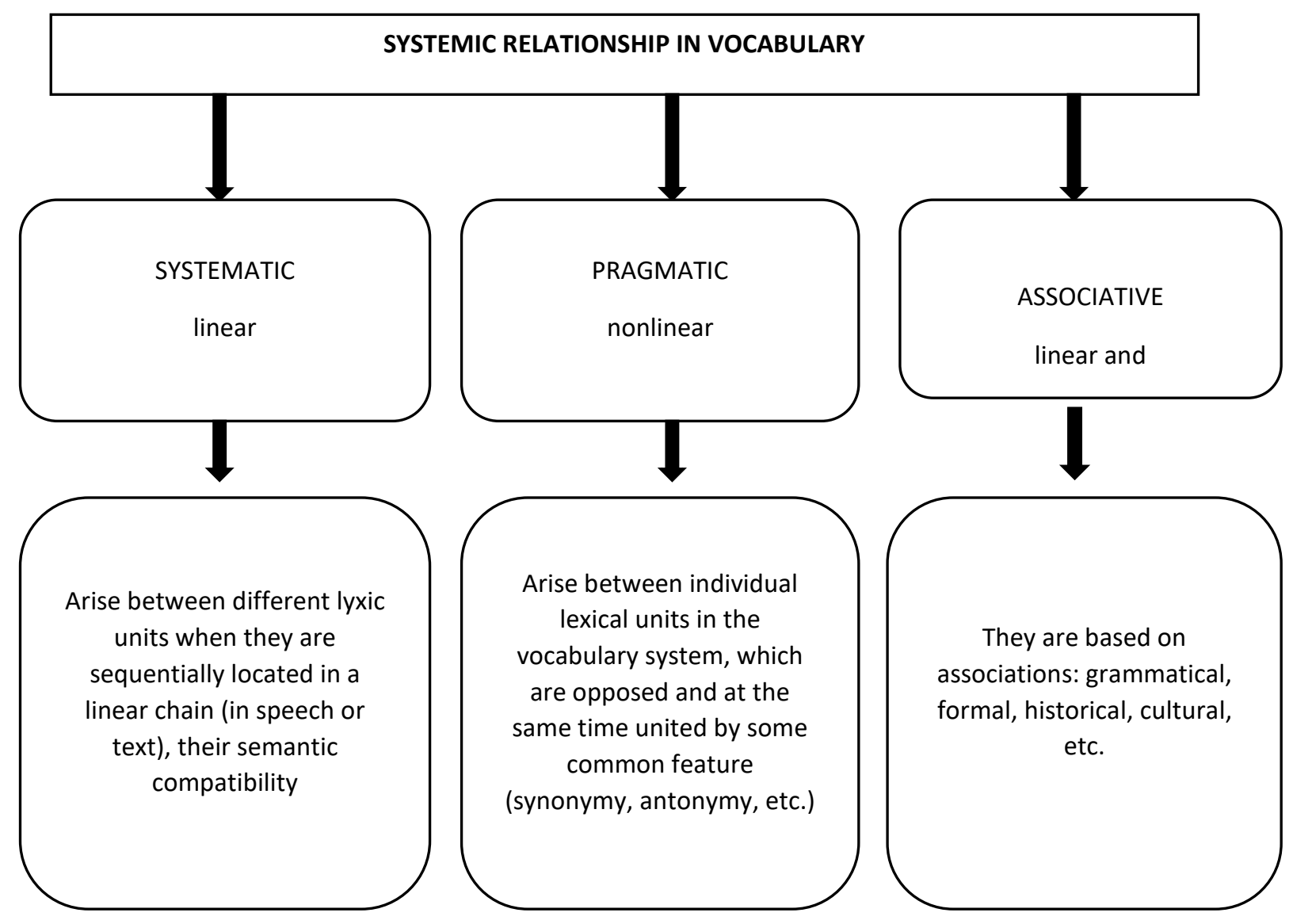

Scheme 1. Systemic relationships in vocabulary.

3. We know the value of water only when the well dries up (B. Franklin). The meaning of the word "water" speaks of its importance in life, water is a "treasure", you need to value it. 
When building vocabulary work by a teacher, it is very important to take into account the syntagmatic relations of vocabulary: mastering a word as a communicative unit, mastering lexical meaning, active use in speech - first of all, allows the child to establish social ties, promotes communication.

In direct connection with syntagmatic, paradigmatic relations are established on the basis of word use and thereby determine the choice of a word for the formation of new word combinations in speech: historicisms, archaisms, neologisms, lexical units with different stylistic colors, etc.

In the lexical system of the language, three parameters are identified, dividing the vocabulary into the following groups:

The lexico-grammatical parameter implies the grammatically correct use of the dictionary, the timely formation of which is the main determinant of the full-fledged mental development of the child.

A formal-semantic parameter is a wordformation nest, that is, a collection of words united by a common root, for example: lie down - lie down - a bed - lying down.

In connection with the study of the role of speech development in the formation of children's creative abilities, let us consider in more detail the semantic parameter of vocabulary.

The study of vocabulary consists in isolating groups and identifying syntagmatic and paradigmatic relations in them. Based on the peculiarities of the lexical semantics of words, the vocabulary is divided into two main groups - thematic (TG) and lexical-semantic (LSG), as well as situational-communicative (SKG) groups of words. Consider the comparative scheme of TG and LSG.

As can be seen from the diagram, a feature of thematic groups (TG) is that words are united not by lexico-semantic connections, but by the classification of the objects and phenomena themselves. Their meaning is expressed mainly by nouns. For example, a spoon, fork, plate, cup are utensils; car, bus, tram, bicycle transport, etc.

The lexico-semantic group (LSG) is a group of words:

- Whose members are united by a semanticparadigmatic relationship (synonymy, antonymy, etc.) and have a dictionary identifier;

- United by belonging to the same part of speech;

- Having comparative lexical meanings;

- Based on a common semantic component;

- Based on differentiation and generalization of contiguous values.

LSG is characterized by the concept of "dictionary identifier", in the role of which are words of general meaning. So, for LSG verbs of motion, the identifier is the word "move"; for LSG verbs of speaking - "to speak", etc. "The vocabulary identifier is the main element of the expanded definition, which manifests the most common, ordinary features defined by the word» [5].

LSM are divided into semantic microgroups. So, the word "speak" can be divided into three microgroups: 1) hypersem "gossip" - talk, gossip, curse, rant, rant; 2) hypersem "talking nonsense" - to fill, grind, shake off, say; 3) hypersem "reprimand" - scold, scold, scold, cheat, smash, etc. As you can see from the example, each microgroup has a common 
semantic feature (to speak) and its own identifiers (gossip, talk nonsense, reprimand).

Some LSGs based on common semantic components - archesems - can be combined into lexical-semantic fields (LSP), consisting of words that belong to different parts of speech. So, in the LSP with the archiseme "state" it is possible to isolate: 1 ) verbs - to be ill, to suffer, to be glad, to worry; 2) nouns - illness, suffering, joy, excitement; 3) adjectives painful, suffering, joyful, exciting; 4) adverbs painful, suffering, joyful, exciting, etc.

As for the LSG, among other features of combining words, it is important to note synonymous series and antonymic pairs, as a lexicographic interpretation of lexical units.

The synonymous row is defined as a system of synonyms, headed by the most capacious and stylistically neutral word - dominant. The synonymous series includes words belonging to one part of speech. For example, nouns - joy, pleasure, celebration, fun, pleasure; adjectives - joyful, happy, cheerful, contented; verb - to rejoice, to be delighted, to enjoy, to celebrate; adverb - joyful, fun, happy, lively, welcoming.

Synonyms are divided into types: semantic (differ in meaning), stylistic (differ in style) and semantic-stylistic (differ in emotional coloring). Semantic synonyms express shades of meaning: red - crimson - scarlet; stylistic ones have the same meaning, but differ in stylistic coloring: smart - sensible - brainy; semanticstylistic differ both in meaning and stylistic coloring: wander - wander - wander. By introducing synonyms into an active dictionary, the child's speech is enriched - words of one synonymous row allow him to learn all the properties of an object or phenomenon, therefore, classes on the development of speech in preschool institutions should include mandatory work on synonyms.

Antonyms are words that have the opposite meaning. Antonymic word pairs always belong to the same part of speech and are related according to some feature: long - short (highquality); few - many (quantitative); day - night (temporary); enter - exit (spatial), etc.

Situational-communicative groups (SCG) of vocabulary imply communication, they are stereotyped, consist of words of different parts of speech, their combinations and standard speech forms. For example, greeting (communication) depends on the participant, time, attitude of the speaker (situation) - we say "Hello" to a friend, and "Hello" to the boss.

Most words in the language have more than one lexical meaning; this phenomenon is called polysemy or polysemy. For example, a lexeme (sound or graphical shell) "to stand up" corresponds to at least eight semes (minimum components of the meaning): 1) take a vertical position; 2) stop; 3) get down to business (get up to the machine); 4) take any pose; 5) climb; 6) take a seat; 7) arise; 8) remember, etc.

It is very important to distinguish polysemy from homonymy, which in most cases is a sound or graphic match of words: "onion" is a vegetable or weapon (sound and graphic match); "Castle" - a palace, fortress or "castle" - a device for locking with a key (graphic coincidence).

Let us now consider such a lexical feature as the direct and figurative meanings of words. The direct (primary) meaning of the word correlates with the subject-conceptual function. The figurative (secondary) meaning appears as a result of polysemy and, although it arises on the basis of a direct one, it differs in 
that it is derivative and motivated. So, the direct meaning of the word "hot" is very warm, overwhelming with heat, the figurative meaning is passionate, melting.

The development of polysemy occurs in three ways:

1. Transfer of a name from one object to another due to the similarity of features (a person's nose - the nose of an airplane).

2. Transfer function (rotary dial phone mobile phone).

3. Metonymy, or transfer of meaning based on real connections - "school", as a building and as a collective (spatial contiguity); "Breakfast" as a meal and as a time interval (temporal contiguity).

The Russian language is alive, and, like all living things, it develops and undergoes changes in the process of its development. In this regard, neologisms periodically appear in a person's speech: 1) on the basis of their own language resources (rover, mobile phone, chip, etc.); 2) based on borrowings from other languages (manager, privatization, exclusive, etc.).

Preschoolers also invent new words based on linguistic patterns. "This is evident from the fact that every normal child often comes up with the same words that are invented by another child at the same age, and the third, and the fourth, and the fifth, because all these words were created according to the same national laws" [7 ].

\section{CONCLUSION}

The great children's writer KI Chukovsky, in his book "From two to five", examines such common childish words: no-no, up-kick, horse, start, everyone, salt with sugar, etc. [7].
The teacher in the classroom on the development of speech should redirect the word-creation of children in the right direction, showing them the current rules of wordformation of their native language.

Phraseological units (idioms), that is, stable phrases, the meaning of which cannot be determined by the meaning of individual words and which have a bright emotional coloring, also contribute to the development of the language. For example, the phraseological unit "to get out of hand" means "to stop listening", "at hand" - "close».

We believe that the key component of the creative development of a preschooler is positive activity, which allows him to go beyond, transforming the surrounding reality. We consider creative development as a dynamic process, during which the child develops an interest in positively transformative activities and he masters universal abilities.

\section{REFERENCES}

1. Ushinsky, KD Native word in 2 hours. Part 1 (Anthology of thought) - - Moscow: Yurayt Publishing House, 2017. - 251 p. - S. 58-64

2. Luria A.R. Basic problems of neurolinguistics 3 rd ed. Publisher: Librokom. Series: From the heritage of world psychology. Year: 2009.256 p.

3. Leontiev, A.A. Fundamentals of Psycholinguistics: Textbook. For university students on specials. "Psychology". / Leontiev A.A. - 4th ed., Rev. - M .; Academia: Smysl, 2005 (State Unitary Enterprise Sarat. Polygraph. Com.). - 287 p. 
4. Nemov, P.C. Psychology In 3 vols. Book. 2. Psychology of education / P.C. Nemov. 2nd ed. - M .: Education: Vlados, 1995 - 496

p.

5. Linguistics. Big Encyclopedic Dictionary / GL ed. By V.N. Yariev .- 2nd ed. M .: Great Russian encyclopedia 2000.-688 p.

6. Kuznetsova, JI.B. Harmonious development of the personality of a younger student: K. for teacher / Kuznetsova LV - M .: Education, 1988.224 s.

7. Chukovsky D.I. From two to five: A book for parents / Chukovsky K.I. - M.: Pedagogika, 1990.- 384 p.. 